\title{
Rubella immunisation history as a guide to immunity
}

\author{
CHARLOTTE E PAUL' AND ELIZABETH S POOLE ${ }^{2}$ \\ From the Department of Preventive and Social Medicine, University of Otago Medical School, Dunedin, and \\ the Virology Department, Dunedin Hospital, Dunedin, New Zealand
}

SUMMARY If rubella immunisation is highly effective accurate recall of past immunisation should enable determination of immune state. The accuracy of recall was studied in a group of young adults aged 16-24 who had been offered Cendehill vaccination at school 10-11 years previously. The subjects were asked whether they had been vaccinated and blood was taken for rubella serology. School records of rubella immunisation were compared with the histories of immunisation. A positive history of immunisation at school was correct in 32 out of 33 cases (97\%). In contrast a negative history was accurate in only 14 out of 43 cases (33\%). Ways of improving the memory of imunisation are needed if this is to be used to determine immune state in young women.

The clinician is faced with the task of ensuring that young women are immune to rubella. In New Zealand, as in the United Kingdom, girls are immunised at school at about the time of puberty, and women in the childbearing years are screened and selectively immunised by their own doctors.

Can the clinician decide on the immune state of a young woman from the history she gives? A history of rubella infection has been shown to be an unreliable indicator of immune state. ${ }^{1}$ Is a history of rubella immunisation a better guide to rubella immunity? Or does rubella antibody titre provide the only useful evidence of immunity?

In this study the existence of school immunisation records provided an unusual opportunity to investigate these quèstions.

\section{Methods}

The study was conducted in May 1981 in Milton, a town of about 2000 people in the South Island of New Zealand. The town had taken part in a study of risk factors for cardiovascular disease, and it was known that about $80 \%$ of the adult population had agreed to participate in previous cross-sectional surveys. $^{2}$ Men and women aged 16-34 were interviewed as part of the larger study. They were questioned about any past history of rubella infection and immunisation, previous screening for rubella immunity, and their knowledge of rubella. This report is mainly confined to those men and women aged 16-24.

Rubella vaccine (Cendehill) was first used in New Zealand in 1970, at which time all girls and boys from primer I to standard 4 (age 5-10 years) were offered immunisation at school. In 1971 girls in form II (age 12-13) were vaccinated. In the period up to 1979 general practitioners vaccinated girls and boys before school entry. In 1979 a new school immunisation programme was introduced, since when girls have been vaccinated at 11 years. Records of immunisation in 1970 and 1971 were kept on the school "progress card," an academic card for every child in State and private schools. The card remained in the final school the child attended. All those in the study aged 24 or younger were questioned about their final school, and the progress cards from those secondary schools in the province were examined.

Blood was taken by venepuncture for rubella serology. The serum was separated and stored at $-20^{\circ} \mathrm{C}$. Haemagglutination-inhibiting (HAI) antibody was determined at the Dunedin Hospital Virus Laboratory. A subsample was tested by the same method at the National Health Institute in Wellington, and agreement was adequate. An HAI titre of $\geqslant 32$ was regarded as immune by both laboratories.

\section{Results}

A total of 444 people aged 16-34 years were interviewed about rubella and had blood taken for rubella antibody determination. These 444 subjects represent $72 \%$ of the population of Milton aged 16-34 (based on the 1976 census).

Of the total group, 191 were born between 1957 and 1965 and were therefore likely to have been offered rubella immunisation in the school 
campaigns of 1970 and 1971 . Table 1 shows that in this age group the overall immunity was $86 \%$ (HAI titre $\geqslant 32$ ). A further $12 \%$ had low antibody levels (HAI titre of 16 ); only $2 \%$ had HAI titre $<16$.

The school records were examined for $152(80 \%)$ of 191 subjects. The records of 39 people were not located, either because they had finished school outside the province or because their school records had been destroyed. Of the 152 records, 114 recorded rubella immunisation at school in 1970 or 1971. The proportion vaccinated ranged from $16 \%$ of those born in 1957 to between $82 \%$ and $100 \%$ of those born in the years 1960-5. Table 2 shows that among those vaccinated at school, $86 \%$ were seropositive (HAI $\geqslant 32$ ). Moreover, none of those immunised had undetectable antibody (HAI <16) compared with $5 \%$ of those not vaccinated at school and $4 \%$ of men aged 25-34 who would not have been vaccinated previously.

Recollection of rubella immunisation was compared with records of immunisation (table 3). In the table those who answered "No" or "unsure" to the question about immunisation at school will include some who thought that they had been vaccinated elsewhere. Of those who thought that they had been vaccinated at school, and for whom school records were available, 32 out of 33 were correct.

Of those who thought that immunisation had not been given at school, only 14 out of $43(38 \%)$ were accurate-that is, they were not immunised at school.

Table 1 Prevalence of rubella antibody in men and women born 1957-65

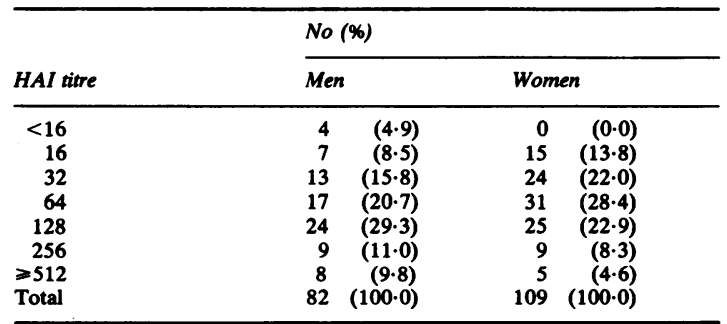

Table 2 Immunity in relation to immunisation at school: men and women born 1957-65

\begin{tabular}{lrrrrrr}
\hline & \multicolumn{2}{l}{ No (\%) } & \multicolumn{3}{l}{} & \\
\cline { 2 - 7 } HAI titre & $\begin{array}{l}\text { Immunised } \\
\text { at school }\end{array}$ & \multicolumn{2}{l}{$\begin{array}{l}\text { Not immunised } \\
\text { at school }\end{array}$} & \multicolumn{1}{c}{ Total } \\
\hline$<16$ & 0 & $(0)$ & 2 & $(5)$ & 2 & $(1)$ \\
16 & 16 & $(14)$ & 4 & $(11)$ & 20 & $(13)$ \\
32 & 22 & $(19)$ & 5 & $(13)$ & 27 & $(18)$ \\
64 & 36 & $(32)$ & 7 & $(18)$ & 43 & $(28)$ \\
128 & 22 & $(19)$ & 13 & $(34)$ & 35 & $(23)$ \\
256 & 12 & $(11)$ & 3 & $(8)$ & 15 & $(10)$ \\
$\geqslant 512$ & 6 & $(5)$ & 4 & $(11)$ & 10 & $(7)$ \\
Total & 114 & $(100)$ & 38 & $(100)$ & 152 & $(100)$ \\
\hline
\end{tabular}

Table 3 Recollection of immunisation in relation to record of immunisation: men and women born 1957-65

\begin{tabular}{|c|c|c|c|c|}
\hline \multirow{2}{*}{$\begin{array}{l}\text { Recollection of } \\
\text { immunisation at } \\
\text { school }\end{array}$} & \multicolumn{2}{|l|}{ No (\%) } & & \\
\hline & $\begin{array}{l}\text { Immunised } \\
\text { at school }\end{array}$ & $\begin{array}{l}\text { Not immunised } \\
\text { at school }\end{array}$ & \multicolumn{2}{|c|}{ Total } \\
\hline Yes & 32 (97) & (3) & 33 & (100) \\
\hline & 29 (67) & 14 (33) & 43 & (100) \\
\hline Unsure & 53 (70) & $23 \quad(30)$ & 76 & (100) \\
\hline Total & 114 (75) & $38 \quad(25)$ & 152 & (100) \\
\hline
\end{tabular}

Those who answered "unsure" when questioned about immunisation at school were equally likely to have been vaccinated as those who gave a negative history, $70 \%$ compared with $67 \%$. Accuracy of positive and negative histories of immunisation was similar among men and women, though many more men $(68 \%)$ than women $(38 \%)$ were unsure of their previous immunisation. Accuracy of recall was influenced by age at which immunisation was offered. Of those who were offered immunisation when under 10 , and who gave a negative history of immunisation, $88.1 \%$ were incorrect, compared with only $45 \%$ of those aged 10-13 at the time of immunisation.

\section{Discussion}

The reliability of a history of rubella immunisation as an indicator of rubella immunity is dependent on two factors: the accuracy of the history and the effectiveness of the vaccine.

A positive history of vaccination was found to be a good indicator of past immunisation in those who had stated that they had been immunised at school. Only one subject wrongly recalled having been vaccinated at school. On the other hand, most of those who gave a negative or doubtful history of immunisation had been vaccinated and had forgotten the event. On the basis of these results, it would be unwise to assume that anyone who thinks she is not immunised is correct. In practice this should encourage clinicians to screen for rubella immunity in adults before immunisation and thus avoid possibly unnecessary repeat vaccinations.

The second consideration is the effectiveness of the vaccine in producing an antibody response and persistent immunity. The recommendations of the Centres for Disease Control ${ }^{3}$ now regard a history of rubella vaccination or any detectable rubella antibody as presumptive evidence of immunity. In this study of those immunised at school all had detectable antibody, but it was not known how many had already been immune before vaccination or how many initially seroconverted. This high level of immunity is comparable with that reported by Just et $a^{4}$ from Switzerland, where only $0 \cdot 8 \%$ of 240 people had undetectable antibody when followed up 
nine years after Cendehill vaccination. In another study from the United States $8 \%$ of those vaccinated had lost detectable antibody seven and a half years after immunisation and primary seroconversion. This discrepancy could be explained by a greater incidence of reinfections in New Zealand, due to circulation of wild virus, particularly during the epidemic of the past two years. ${ }^{6}$

Low levels of antibody (HAI $=16)$ were found in $14 \%$ of subjects immunised at school, and in only $4 \%$ of an unimmunised group (men aged 25-34 in this study). This is a significant difference $\left(\chi_{1}^{2}=5 \cdot 7\right.$. $p<0.02)$. These low levels of HAI antibody are compatible with vaccine-induced immunity, and have been found in other studies. ${ }^{7-9}$ It is still uncertain whether the immunity of this group will wane so that they become susceptible to viraemic infection, ${ }^{10}$ and to what extent the HAI test may give false-positive results at low titres by some methods. ${ }^{11}$

The introduction of better vaccines and the improvements in the specificity and sensitivity of testing for rubella ${ }^{11}$ mean that rubella vaccination may be shown to be highly effective. The recent study by Zealley and Edmond ${ }^{9}$ showed that only $1.05 \%$ of subjects were seronegative by radioimmunoassay six to seven years after vaccination with RA27/3. Hence, in the future, accuracy of recall may be the crucial factor in determining rubella immunity from vaccination history.

The study showed that the positive recollection of past immunisation at school was remarkably accurate, and suggests that this may be a useful guide to immunisation state. Most subjects, however, simply forgot their previous immunisation. This was most likely to happen to those who were immunised before 10 years of age. Rubella vaccination of schoolgirls is now routinely offered at 11 in New Zealand, and between 10 and 14 in the United Kingdom. At these ages it should be more realistic to expect girls to remember that they have been immunised. Health educationalists might consider ways by which this memory could be improved. One recent practical suggestion ${ }^{12}$ is that all schoolgirls might be provided with a card on which to record their immunisation and immune state.

We thank the New Zealand Department of Health for help and advice, Mr George Spears for help with the data analysis, and Professor D C G Skegg for advice. We thank Professor F. O Simpson for kindly enabling us to study the Milton population.

\section{References}

${ }^{1}$ Evans AS. The need for serologic evaluations of immunisation programs. Am J Epidemiol 1980; 112: 725-31.

${ }^{2}$ Simpson FO, Nye ER, Bolli $\mathrm{P}$, et al. The Milton survey: part I, general methods, height, weight and 24 hour excretion of sodium, potassium, calcium, magnesium and creatinine. $N Z$ Med $J$ 1978; 87: 379-82.

${ }^{3}$ Anonymous. Rubella prevention. Morbidity and Mortality Weekly Report 1981; 30: 37-47.

4 Just M, Berger-Hernandez R, Bürgin-Wolff A. Serum antibodies 9 years after Cendehill rubella immunisation. Lancet 1977; ii: 1349-50.

${ }^{5}$ Schiff GM, Rauh JL, Young B, Trimble S, Rotte T, Schiff B. Rubella vaccinated students: follow-up in a public school system. JAMA 1978; 240: 2635.

${ }^{6}$ Department of Health. The public health. Wellington: Department of Health, 1981: 28.

${ }^{7}$ Horstmann DM. Controlling rubella: problems and perspectives. Ann Intern Med 1975; 83: 412-7.

${ }^{8}$ Zealley $\mathrm{H}$. Rubella screening and immunisation of school girls: a long-term evaluation. Br J Prev Soc Med 1974; 28: 54-9.

${ }^{9}$ Zealley $\mathrm{H}$, Edmond E. Rubella screening and immunisation of school girls: results six to seven years after vaccination. $\mathrm{Br}$ Med J 1982; 284: 382-4.

${ }^{10}$ Balfour HH, Groth EK, Edelman CK, Amren DP, Best JM, Banatvala JE. Rubella viraemia and antibody responses after rubella vaccination and reimmunisation. Lancet 1980; i: 1078-80.

${ }^{11}$ Best JM, Harcourt GC, Druce A, Palmer SJ, O'Shea S, Banatvala JE. Rubella immunity by four different techniques: results of challenge studies. $J$ Med Virol 1980; 5: 239-47.

${ }^{12}$ Gilmore D, Robinson ET, Gilmore WH, Urquhart GED. Effect of rubella vaccination programme in schools on rubella immunity in a general practice population. $\mathrm{Br}$ Med J 1982; 284: 628-30. 